\title{
A comparison of the clinical effects and safety between the distal radial artery and the classic radial artery approaches in percutaneous coronary intervention
}

\author{
Hui Wang, Wen-Jin Peng, Yan-Hong Liu, Guan-Qun Ma, Dan Wang, Bin Su, Ying-Wu Liu \\ Department of Cardiology, Tianjin Third Central Hospital, Tianjin, China \\ Contributions: (I) Conception and design: YW Liu; (II) Administrative support: None; (III) Provision of study materials or patients: H Wang, WJ \\ Peng; (IV) Collection and assembly of data: YH Liu, GQ Ma; (V) Data analysis and interpretation: D Wang, B Su; (VI) Manuscript writing: All \\ authors; (VII) Final approval of manuscript: All authors. \\ Correspondence to: Ying-Wu Liu, PhD. Department of Cardiology, Tianjin Third Central Hospital, No. 83 of Jintang Road, Hedong District, Tianjin \\ 300170, China. Email: liuyingwu33@163.com.
}

\begin{abstract}
Background: Compared with a classic wrist puncture for radial artery catheterization, a distal radial artery puncture has the advantage of reducing the incidence of radial artery occlusion in anatomic and physiological procedures. This study aimed to explore the difference in clinical effects between the distal radial artery and classic radial artery approaches in percutaneous coronary intervention.
\end{abstract}

Methods: A total of 620 patients who underwent coronary angiography and/or percutaneous coronary intervention in our hospital from December 2017 to December 2018 were enrolled in this study. These patients were divided into two groups based on the puncture site: a distal radial artery group and a classic radial artery group. There were 312 patients in the radial artery group and 308 patients in the classic radial artery group. The puncture time, puncture success rate, surgery time, implanted stents, puncture site hemorrhage, hematoma, aneurysm, and iliac artery occlusion rate were observed.

Results: There was no significant difference in puncture time, puncture success rate, surgery time, implanted stent, puncture site hemorrhage, hematoma and aneurysm $(\mathrm{P}>0.05)$, while the radial artery occlusion rate was lower in the distal radial artery group, and the difference was statistically significant $(\mathrm{P}<0.05)$.

Conclusions: The results of this study showed that the distal radial artery approach had a lower rate of brachial artery occlusion, indicating that it could be used as an alternative to the classic radial artery approach.

Keywords: Distal radial artery; classic radial artery; percutaneous coronary intervention; radial artery occlusion

Submitted Nov 11, 2019. Accepted for publication May 29, 2020.

doi: 10.21037/apm-19-479

View this article at: http://dx.doi.org/10.21037/apm-19-479

\section{Introduction}

In recent years, with the development of percutaneous coronary intervention, transradial coronary intervention (TRI) has surpassed transfemoral coronary intervention to become the preferred approach for percutaneous coronary intervention (1). Existing studies demonstrate that vascular complication and bleeding incidence has a direct relationship with the postoperative short-term and long-term survival rates of patients $(2,3)$. Compared with transfemoral coronary intervention, TRI has advantages such as low incidence of puncture vascular complications, early ambulation, less bleeding, and is easily accepted by patients. Based on selected randomized studies, TRI is considered the default technique for coronary intervention (4).

Radial artery occlusion is a common vascular complication following TRI, with an incidence of approximately 1-12\% 
(2-5). Due to the dual arterial supply to the hand, radial artery occlusion is generally asymptomatic and overlooked, though at times it may be associated with paresthesia, pain at the site of occlusion, loss of hand function, and distal ischemia (6). Determining how to reduce vascular complications and postoperative radial artery occlusion remains an issue that requires additional research.

Compared with a classic wrist puncture for radial artery catheterization, distal radial artery puncture has the advantage of reducing the incidence of radial artery occlusion in anatomic and physiological principles (7). However, outcome comparisons between these two methods remain lacking.

In this context, the current researchers attempted to puncture the distal radial artery for coronary artery intervention compared with the classic radial artery approach to explore the clinical effects and safety of the distal radial artery approach, and to assess whether it may be a better and novel option for coronary artery intervention.

We present the following article in accordance with the STROBE reporting checklist (available at: http://dx.doi. org/10.21037/apm-19-479).

\section{Methods}

\section{General information}

A total of 620 patients who underwent percutaneous coronary intervention in our hospital for the first time from December 2017 to December 2018 were selected as study subjects. These patients were divided into two groups based on the puncture site: 312 patients who underwent percutaneous coronary intervention via the distal radial artery were enrolled in the distal radial artery puncture group; 308 patients who underwent percutaneous coronary intervention via the classic radial artery were enrolled in the radial artery puncture group. The trial was conducted in accordance with the Declaration of Helsinki (as revised in 2013). The study was approved by committee board of Tianjin Third Central Hospital and informed consent was taken from all the patients.

\section{Distal radial artery puncture group}

Prior to surgery, the Allen test was conducted on the bilateral radial artery of the patients in this group, and the bilateral blood supply recovery status was compared. The side with a faster recovery rate was selected as the operative side, and all the patients were provided with a load capacity of $300 \mathrm{mg}$ of aspirin and $300 \mathrm{mg}$ of clopidogrel $(180 \mathrm{mg}$ of ticagrelor) prior to undergoing surgery.

Following the completion of routine disinfection, the tabatiere anatomique area was selected as the puncture site (Figure 1A), and 1\% lidocaine was used for local anesthesia. The Seldinger method was used to make the puncture on the distal radial artery. Following successful puncture, a $6 \mathrm{~F}$ artery sheath was placed (Figure $1 B$ ) and 4,000 U of heparin was injected into the sheath. Next, coronary angiography was conducted. Following the completion of the intervention, the artery sheath was removed; a piece of gauze folded three times was used to cover the puncture site. Concurrently, three elastic bandages were used in a crosswise manner as a pressure bandage (Figure $1 C$ ). One elastic bandage was removed every two hours, and the compression was completely relieved after six hours (Figure 1D).

\section{Radial artery puncture group}

Prior to surgery, the Allen test was conducted on the bilateral radial artery of the patients in this group and the bilateral blood supply recovery status was compared. The side with a faster recovery rate was selected as the operative side. All patients were provided with a load capacity of $300 \mathrm{mg}$ of aspirin and $300 \mathrm{mg}$ of clopidogrel $(180 \mathrm{mg}$ of ticagrelor) prior to surgery. Following the completion of routine disinfection, the area at approximately $2 \mathrm{~cm}$ adjacent to the proximal end of the lateral wrinkle of the palm (the area with the highest radial artery fluctuation intensity) was used as the puncture site (Figure $2 \mathrm{~A}$ ) and $1 \%$ lidocaine was used as a local anesthetic. The Seldinger method was used to make the puncture on the radial artery. Following successful puncture, a $6 \mathrm{~F}$ radial artery sheath was placed (Figure 2B), and 4,000 $\mathrm{U}$ of heparin was injected into the sheath. Then, the coronary angiography was conducted, and the contrast agent dosage used during the procedure was recorded. After completion of the intervention, the artery sheath was removed, and an air pressure tourniquet (TERUMO; Model: XX*RF06; Batch no.: 180320) was immediately used to conduct hemostasis by compression on the puncture site (Figure 2C). Air was released once every 2 hours to alleviate the pressure; compression was completely relieved after six hours (Figure 2D).

\section{Clinical observation index and result judgment standard}

The average puncture time, puncture success rate, surgery 

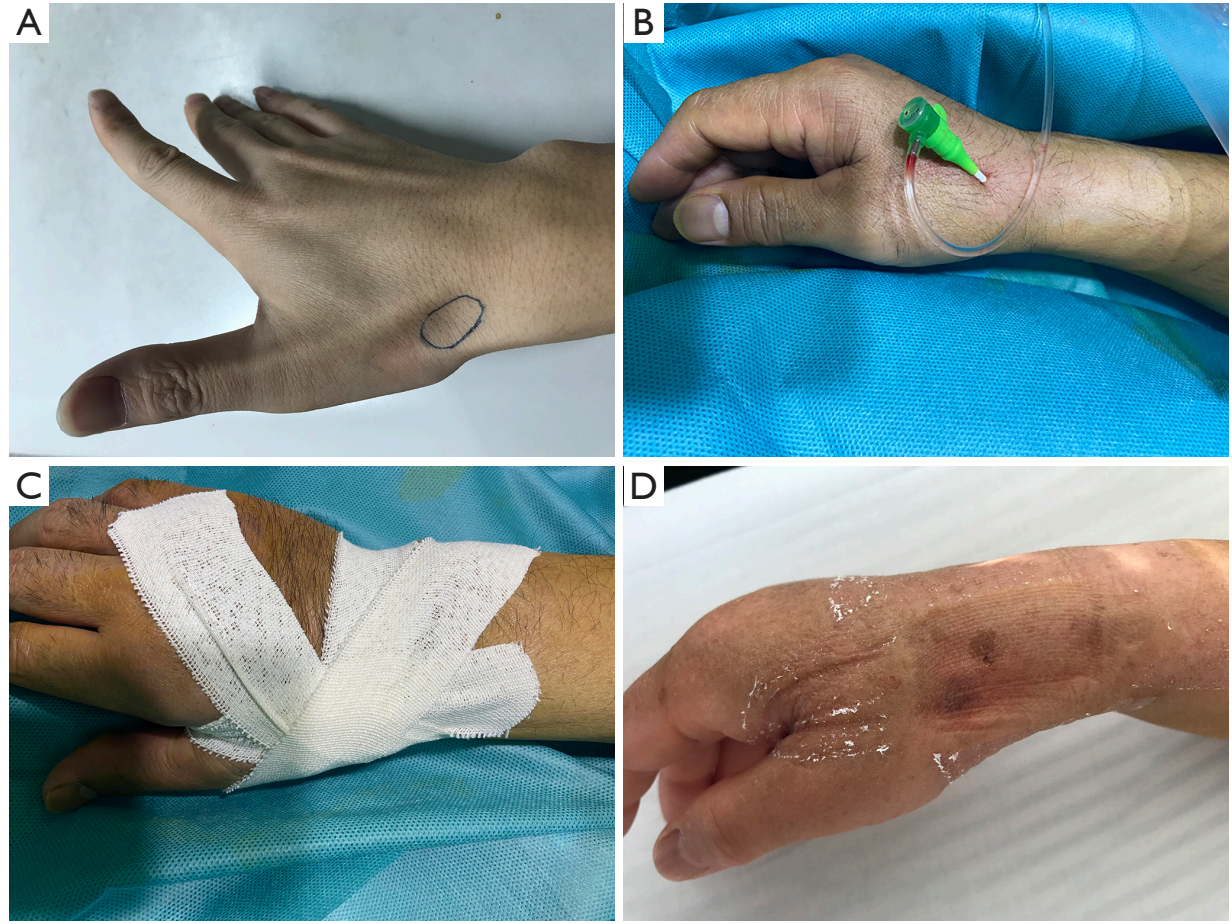

Figure 1 Distal radial artery puncture method. (A) The puncture site of the tabatiere anatomique location; (B) the 6F artery sheath implantation; (C) the compression bandage with an elastic bandage (Youlishu) after the intervention; (D) the puncture site recovery status.
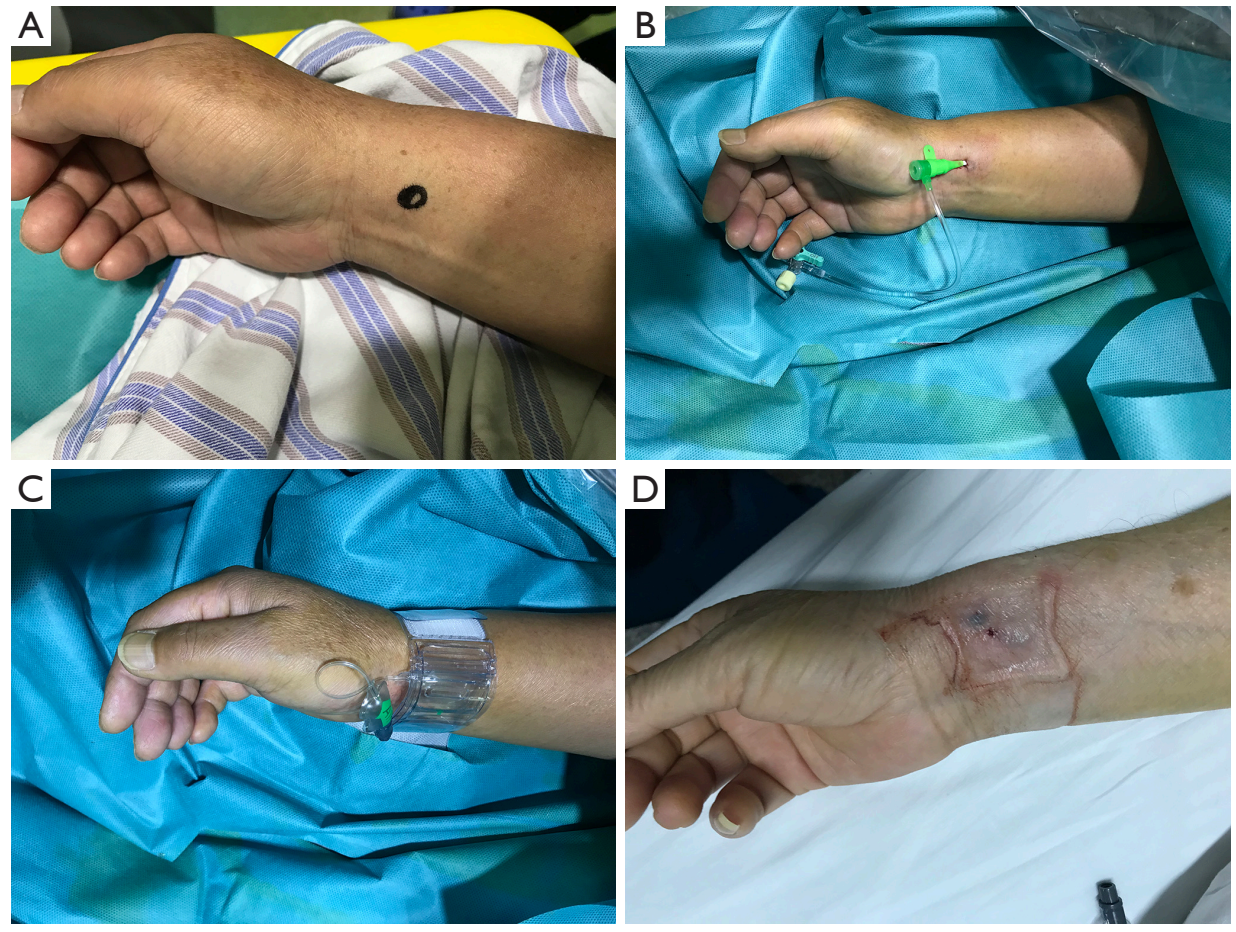

Figure 2 Classic radial artery puncture method. (A) The recovery status of the puncture site; (B) the 6F artery sheath implantation; (C) the tourniquet compression bandage; (D) the recovery status of the puncture site after the intervention. 
Table 1 Comparison of baseline characteristics between two groups

\begin{tabular}{lcc}
\hline Item & Distal radial artery group $(\mathrm{n}=312)$ & Classic radial artery $(\mathrm{n}=308)$ \\
\hline Age, years & $50.1 \pm 7.2$ & $51.2 \pm 7.3$ \\
Male, case & 160 & 157 \\
Female, case & 152 & 151 \\
Hypertension, $\mathrm{n}(\%)$ & $189(60.6)$ & $174(56.5)$ \\
Diabetes, $\mathrm{n}(\%)$ & $98(31.4)$ & $87(28.2)$ \\
Hyperlipidemia, $\mathrm{n}(\%)$ & $138(44.2)$ & $129(41.9)$ \\
Smoking, $\mathrm{n}(\%)$ & $176(56.4)$ & $168(54.5)$ \\
\hline
\end{tabular}

There was no significant difference between the two groups $(P>0.05)$.

time, and implanted stent for patients in the two groups were compared. The incidence of radial artery spasm, hematoma, and artery aneurysm in patients, and the incidence of radial artery occlusion prior to discharge were also recorded. Result judgment standards are given as follows: (I) successful radial artery puncture-following the radial artery puncture, the artery sheath was inserted; (II) radial artery puncture time-the time from initial local infiltration anesthesia to sheath insertion; (III) radial artery spasm-it was impossible to conduct a radial artery puncture; alternatively, although the puncture was successful, it was impossible to complete the surgery; (IV) radial artery occlusion-color ultrasound verified that the radial artery had no forward blood flow.

\section{Statistical analysis}

The SPSS statistical software package (v.22.0) was used to conduct statistical analysis, and an $\chi^{2}$-test and $t$-test were used for the enumeration data and measurement data, respectively. Here, $\mathrm{P}<0.05$ was considered to represent a statistically significant result.

\section{Results}

\section{Comparison of the baseline data of patients in the two} groups

For the distal radial artery puncture group, 160 patients were male, and 152 patients were female, and the mean age of these patients was $50.1 \pm 7.2$ years old. For the radial artery puncture group, 157 patients were male, and 151 patients were female, and the mean age of these patients was $51.2 \pm 7.3$ years old. There was no significant difference in the case number, gender, age, hypertension, diabetes, hyperlipemia, and blood vessel diameter of patients in the two groups $(\mathrm{P}>0.05$; see Table 1$)$. Hence, the baseline data of the two groups were comparable.

\section{Comparison of the operative effects among patients in the two groups}

There was no significant difference in the puncture success rate, average puncture time, surgery time, implanted stent, and vessel diameter of patients in these two groups $(\mathrm{P}>0.05$; see Table 2).

\section{Comparison of complications among the patients in the two groups}

The radial artery occlusion rate of patients in the distal radial artery group was significantly lower than in the classic radial artery puncture group, and the difference was statistically significant $(\mathrm{P}<0.05)$.

The comparisons for intraoperative radial artery spasm, postoperative hematoma, arterial aneurysm, and arteriovenous fistula revealed no statistically significant difference $(\mathrm{P}>0.05$; see Table 3$)$.

\section{Discussion}

In the past two years, doctors performing coronary artery intervention have attempted to adopt the distal radial artery approach (8-11). Anatomic and physiological principles suggested the distal radial artery as an innovative approach for assessing coronary and endovascular procedures in existing studies (7). The distal radial artery, located at the 
Table 2 Comparison of effects after coronary intervention between two groups

\begin{tabular}{|c|c|c|c|c|c|}
\hline Groups & $\begin{array}{l}\text { Vessel diameter } \\
\qquad(\mathrm{mm})\end{array}$ & $\begin{array}{l}\text { Average puncture } \\
\text { time (min) }\end{array}$ & $\begin{array}{c}\text { Puncture success } \\
\text { rate, } \mathrm{n}(\%)\end{array}$ & $\begin{array}{l}\text { Operation } \\
\text { time (min) }\end{array}$ & $\begin{array}{c}\text { Implanted } \\
\text { stent }(\mathrm{N})\end{array}$ \\
\hline Distal radial artery group $(n=312)$ & $2.2 \pm 0.5$ & $5.4 \pm 1.6$ & $296(94.9)$ & $50.0 \pm 8.3$ & $1.7 \pm 0.4$ \\
\hline Classic radial artery $(n=308)$ & $2.4 \pm 0.4$ & $5.6 \pm 1.4$ & $295(95.8)$ & $51.0 \pm 7.9$ & $1.6 \pm 0.5$ \\
\hline$P$ & 0.684 & 0.734 & 0.894 & 0.564 & 0.785 \\
\hline
\end{tabular}

Table 3 Comparison of radial artery complications after coronary intervention between two groups

\begin{tabular}{|c|c|c|c|c|c|c|}
\hline Groups & $\begin{array}{l}\text { Radial artery } \\
\text { spasm }\end{array}$ & $\begin{array}{c}\text { Postoperative } \\
\text { hematoma }\end{array}$ & $\begin{array}{c}\text { Arterial } \\
\text { aneurysm }\end{array}$ & Arterio-venous-fistula & $\begin{array}{c}\text { Radial artery } \\
\text { occlusion }\end{array}$ & Total \\
\hline Distal radial artery group $(n=312), n(\%)$ & $9(2.9)$ & $4(1.3)$ & $0(0)$ & $1(0.3)$ & $6(1.9)$ & $20(6.4)$ \\
\hline$P$ & 0.542 & 1.000 & 1.000 & 1.000 & 0.031 & 0.013 \\
\hline
\end{tabular}

tabatiere anatomique area, is relatively thick and large with fixation, with an inner diameter of approximately $2 \mathrm{~mm}$. It is located at the proximal end of the thumb artery. Even when radial artery occlusion complications occur, it will not affect the blood supply to the thumb, thereby making it possible to use the distal radial artery in intervention approaches.

The reasons for radial artery occlusion primarily include extended compression time, inflammatory reaction, and thrombosis. In this study, the radial artery occlusion rate in the distal radial artery group and classic radial artery group was $1.9 \%$ and $5.19 \%$, respectively. As expected, the radial artery occlusion rate in the distal radial artery group was much lower $(\mathrm{P}<0.05)$. The possible reasons for the lower occlusion rate in this group are as follows: (I) the location of the distal radial artery was relatively superficial, and the compression tension using gauze was small; (II) the distal radial artery is part of the bilateral blood supply, making it unsuitable for occlusion (7). Except for radial artery occlusion, the incidence of other complications such as radial artery spasm, hematoma, arterial aneurysm, and arteriovenous fistula was not significantly different between the two groups $(\mathrm{P}>0.05)$. In addition, the puncture success rate, puncture time, and operation time between the two groups were not significantly different $(\mathrm{P}>0.05)$. Thus, compared with classic radial artery puncture intervention, the distal radial artery intervention approach appears more convenient for hemostasis with a lower radial artery occlusion rate.
Currently, many studies pertaining to distal radial artery puncture in the coronary artery intervention process have verified the safety of this approach (5). The most recent guidance from Europe and Brazil regards the distal radial artery approach as the preferred path for coronary arterial intervention (12,13). Boncoraglio et al. (14) reported that distal radial artery puncture showed a good degree of safety in the emergency coronary artery intervention process for elderly patients. Our study also suggested that distal radial artery intervention can be used as an alternative path to the classic radial artery approach. For patients where performing a puncture on the routine radial artery site was unsuitable, an attempt to conduct a distal radial artery puncture could be made.

The present study had several limitations. Since the case number of enrolled patients in the present study was relatively low, and all patients were derived from a single health center, a bias may have been present in the patient selection. If this was the case, this study cannot be considered a randomized controlled trial (RCT). Thus, to further assess the effects and safety of distal radial artery puncture in coronary artery intervention, more theoretical evidence is required for its clinical application, alongside an RCT with a sufficient number of patients.

In conclusion, in this study, the distal radial artery approach had a lower rate of brachial artery occlusion, indicating that it can be used as an alternative to the classic radial artery approach. 


\section{Acknowledgments}

We are particularly grateful to all the people who have given us help on our article.

Funding: Tianjin Science and Technology Project (No. 16ZXMJSY00200).

\section{Footnote}

Reporting Checklist: The authors have completed the STROBE reporting checklist. Available at http://dx.doi. org/10.21037/apm-19-479

Data Sharing Statement: Available at http://dx.doi. org/10.21037/apm-19-479

Conflicts of Interest: All authors have completed the ICMJE uniform disclosure form (available at http://dx.doi. org/10.21037/apm-19-479). The authors have no conflicts of interest to declare.

Ethical Statement: The authors are accountable for all aspects of the work in ensuring that questions related to the accuracy or integrity of any part of the work are appropriately investigated and resolved. The trial was conducted in accordance with the Declaration of Helsinki (as revised in 2013). The study was approved by committee board of Tianjin Third Central Hospital and informed consent was taken from all the patients.

Open Access Statement: This is an Open Access article distributed in accordance with the Creative Commons Attribution-NonCommercial-NoDerivs 4.0 International License (CC BY-NC-ND 4.0), which permits the noncommercial replication and distribution of the article with the strict proviso that no changes or edits are made and the original work is properly cited (including links to both the formal publication through the relevant DOI and the license). See: https://creativecommons.org/licenses/by-nc-nd/4.0/.

\section{References}

1. Valgimigli M, Gagnor A, Calabró $\mathrm{P}$, et al. Radial versus femoral access in patients with acute coronary syndromes undergoing invasive management: a randomised multicentre trial. Lancet 2015;385:2465-76.

2. Sławin J, Kubler P, Szczepański A, et al. Radial artery occlusion after percutaneous coronary interventions - an underestimated issue. Postepy Kardiol Interwencyjnej 2013;9:353-61.

3. Lisowska A, Knapp M, Tycińska A, et al. Radial access during percutaneous interventions in patients with acute coronary syndromes: should we routinely monitor radial artery patency by ultrasonography promptly after the procedure and in long-term observation? Int J Cardiovasc Imaging 2015;31:31-6.

4. Agostoni P, Biondi-Zoccai GG, de Benedictis ML, et al. Radial versus femoral approach for percutaneous coronary diagnostic and interventional procedures; Systematic overview and meta-analysis of randomized trials. J Am Coll Cardiol 2004;44:349-56.

5. Soydan E, Akın M. Coronary angiography using the left distal radial approach - An alternative site to conventional radial coronary angiography. Anatol J Cardiol 2018;19:243-8.

6. Wagener JF, Rao SV. Radial artery occlusion after transradial approach to cardiac catheterization. Curr Atheroscler Rep 2015;17:489.

7. Sgueglia GA, Di Giorgio A, Gaspardone A, et al. Anatomic Basis and Physiological Rationale of Distal Radial Artery Access for Percutaneous Coronary and Endovascular Procedures. JACC Cardiovasc Interv 2018;11:2113-9.

8. Valsecchi O, Vassileva A, Cereda AF, et al. Early Clinical Experience With Right and Left Distal Transradial Access in the Anatomical Snuffbox in 52 Consecutive Patients. J Invasive Cardiol 2018;30:218-23.

9. Kim Y, Jeong MH, Kim I, et al. Intravascular UltrasoundGuided Percutaneous Coronary Intervention with Drugeluting Stent for Unprotected Left Main Disease via Left Snuffbox Approach. Korean Circ J 2018;48:532-3.

10. Berezhnoi K, Kokov L, Vanyukov A, et al. Complete revascularization via left snuffbox approach in a nonagenarian patient with acute myocardial infarction. Cardiol J 2018;25:530-1.

11. Kim Y, Jeong MH, Berezhnoi K, et al. Recannulation of Distal Radial Artery for Staged Procedure After Successful Primary Percutaneous Coronary Intervention. J Invasive Cardiol 2018;30:E105-6.

12. Arslan F, Bongartz L, Ten Berg JM, et al. 2017 ESC guidelines for the management of acute myocardial infarction in patients presenting with ST-segment elevation: comments from the Dutch ACS working group. Neth Heart J 2018;26:417-21.

13. Feres F, Costa RA, Siqueira D, et al. Guideline of the 
Brazilian Society of Cardiology and the Brazilian Society of Hemodynamics and interventional cardiology on percutaneous coronary intervention. Arq Bras Cardiol 2017;109:1-81.

Cite this article as: Wang H, Peng WJ, Liu YH, Ma GQ, Wang D, Su B, Liu YW. A comparison of the clinical effects and safety between the distal radial artery and the classic radial artery approaches in percutaneous coronary intervention. Ann Palliat Med 2020;9(5):2568-2574. doi: 10.21037/apm-19-479
14. Boncoraglio A, Caltabiano G, Foti PV, et al. Distal radial artery: The last extreme rescue arterial access for interventional radiologists? SAGE Open Med Case Rep 2019;7:2050313X18823918. 